\section{The prevalence of psoriasis among elderly individuals: more questions than answers}

\author{
loannis D. Bassukas, \\ Konstantina A. Mavridou, \\ Theocharis Evangelou, Georgios Gaitanis \\ Department of Skin and Venereal \\ Diseases, University of Ioannina Medical \\ School, loannina, Greece
}

\section{Abstract}

Knowledge of epidemiological data of psoriasis among elderly people is limited. Herein the prevalence of psoriasis among non-permanently hospitalized, elderly (70-89 year old) individuals was assessed by a face-to-face interview using a structured questionnaire adapted from an earlier telephone survey elsewhere. 450 individuals 70-89 years old consented to contribute. Psoriasis was found in 15/450 individuals [life-long prevalence: 3.33\%; (95\% confidence intervals: 1.99$5.47 \%)$ ]; $1 / 450$ individuals have ever required systemic treatment $(0.2 \%$ [0.01-1.4\%]). This prevalence is about ten times higher than corresponding results of the aforementioned telephone survey with the same questionnaire. In conclusion this study: i) Provides the first estimation of psoriasis prevalence in Greece, albeit focused in a particular age group and demonstrates a relatively high life-long prevalence, however with minimal morbidity among older people; ii) Underscores the need for studies to evaluate the impact of proxy effects (e.g. telephone information) in assessing skin morbidity of older probands.

\section{Introduction}

Skin diseases are a quite common health problem with a high need for treatment among adults worldwide. ${ }^{1-4}$ Epidemiological studies of dermatological entities in elderly people are limited although the burden of skin related complains and disorders increases significantly as a function of age to become a considerable source of disability for the oldest. ${ }^{4-9}$

Psoriasis, as a consequence of its chronicity and lack of definitive cure, is worldwide one of the most prevalent immune-mediated skin disease in adults. ${ }^{10-12}$ The severity and course of psoriasis, a papulosquamous inflammatory disease with variable clinical morphology, depends on both genetic and environmental factors. ${ }^{13}$ Direct morbidity of psoriasis is moderate, however the disease negatively impacts health-related quality of life in a substantial degree. ${ }^{13-15}$ Psoriasis is not curable, yet data on the burden of psoriasis in elderly people are scanty and controversial.11 Herein we report the results of a survey on the prevalence of psoriasis in non-permanently hospitalized, elderly (70-89 year old) individuals.

\section{Materials and Methods}

The study was performed by the method of the face-to-face interview with a structured questionnaire in a KAPI unit located in Ioannina, an urban community in Greece. KAPI is an Open Care Community Center for Older People which in Greece represents a nationwide network of multidisciplinary centers, providing social and primary health services to older members of the local community, together with recreational and group activities on a volunteer basis. ${ }^{16}$ After permission from the Municipal Authorities and following oral consent all individuals, that personally contacted the KAPI medical service between March 01 and April 30, 2010 were interviewed for the presence (active disease) or personal history of psoriasis using a structured questionnaire adapted according to that used previously by Ferrándiz et al. in a telephone psoriasis survey in Spain. ${ }^{17}$ For the probands, main reasons for attending the medical service of KAPI were to renew prescriptions of routine medications and/or to carry out simple periodic examinations, like blood pressure measurements. The files of all contacted individuals were additionally reviewed for past prescriptions ascribed to the treatment of psoriasis. SPSS 17.0 (Chicago, IL, USA) was employed to calculate core demographic data and prevalence rates with $95 \%$ confidence intervals.

\section{Results}

A total of 628 individuals attended the medical service of KAPI during the survey period and were asked to participate to this study. From the 601 individuals (96\%), who consented to participate, 450 (75\%) aged between 7089 years (mean/median age: 78/77 years respectively). Sixty-three percent (63\%) of the probands were females, roughly reflecting gender composition of the Greek population at this age group. Psoriasis was identified in 15/450 individuals (prevalence: 3.33\%; [95\% confidence intervals (95\% CI): 1.99-5.47\%]; Table 1). Psoriasis tended to be more frequent among men. The life-long prevalence of psoriasis episodes requiring systemic treatment was quite low ( $1 / 450$ individuals or about $0.2 \%$ [95\% CI: 0.01-1.4\%]): Only one patient, though
Correspondence: Ioannis D. Bassukas, Dept Skin \& Venereal Diseases, Univ. Ioannina Medical School, Univ. Campus, GR-45110 Ioannina, Greece.

Tel. +30.2651 .007425 - Fax: +30.2651 .007031 .

E-mail: ibassuka@cc.uoi.gr

Key words: skin diseases, psoriasis, prevalence, elderly, proxies.

Acknowledgments: the authors gratefully acknowledge the contribution of M.S. Bakola, $\mathrm{MD}$, to the electronic data processing.

Contributions: IBD, GG study concept; KAM, TE data collection; IBD statistical analysis performing and first draft of the manuscript writing.

Conflict of interest: the authors report no conflicts of interest.

Received for publication: 10 December 2010. Accepted for publication: 6 March 2011.

This work is licensed under a Creative Commons Attribution 3.0 License (by-nc 3.0).

CC Copyright I.D. Bassukas et al., 2011

Ageing Research 2011; 3:el

doi:10.4081/ar.2011.el

presently in remission, reported recurrent moderate-to-severe disease flairs in the past that needed systemic treatment (PUVA, methotrexate and retinoids on different occasions). To the rest of the patients (14/15) psoriasis was adequately controlled throughout their lifetime with topical medications.

\section{Discussion}

This is the first study that appraises the prevalence of psoriasis in Greece, albeit focused in an age group with limited and nevertheless controversial reported prevalence data in the literature. ${ }^{10,11}$ To date, some surveys have measured the highest age-specific prevalence of psoriasis in older individuals, ${ }^{18,19}$ as expected for a chronic disease with onset throughout life and almost negligible disease-specific excess mortality. ${ }^{19}$ Yet other studies found leveling off or even drastically declining rates of psoriasis prevalence for individuals beyond the age of 70 years compared to younger age classes.17,21-25 Thus, in contrast to the relatively high prevalence measured herein, a nation-wide telephone survey in Spain applying essentially the same structured questionnaire recorded only $0.33 \%$ age-specific prevalence in persons $>70$ years old. This was only a quarter of the average psoriasis prevalence measured in the whole target population of this latter study or just one seventh of the highest prevalence rate that was found for age 
Table 1. Prevalence of psoriasis among elderly (70-89 years old), non-permanently hospitalized individuals

\begin{tabular}{|c|c|c|c|}
\hline $\begin{array}{l}\text { Probands } \\
\text { Gender }\end{array}$ & $\begin{array}{l}\text { Individuals } \\
\text { with psoriasis }\end{array}$ & $\begin{array}{l}\text { Individuals } \\
\text { without psoriasis }\end{array}$ & Total \\
\hline Female & 6 & $\begin{array}{c}278 \\
(2.11 \%[0.86-4.64])^{*}\end{array}$ & 284 \\
\hline Male & 9 & $\begin{array}{c}157 \\
(5.73 \%[2.90-10.68])\end{array}$ & 166 \\
\hline Total & $\begin{array}{c}15 \\
(3.33 \%[1.99-5.47])\end{array}$ & 435 & 450 \\
\hline
\end{tabular}

*Parentheses: Gender-specific and total prevalence of psoriasis in \% [ $95 \%$ confidence intervals].

subpopulation 30-40 years old.17 Telephone surveys answered by proxies is a reliable and generally valuable source of information about health conditions of older probands. ${ }^{26}$ However, the accuracy of information acquired by proxies - excluded herein by interviewing all probands - varies significantly according to the health area assessed by the telephone survey. 27,28 This could at least partly explain the despite divergent ground populations - unexpected high discrepancy between the estimations of psoriasis prevalence in the elderly found with the same questionnaire in the present face-to-face interview and the former telephone survey study. 17 Furthermore, this observation underscores the difficulties in measuring skin-related morbidity of older probands by using proxies sources, and calls for research focusing on the evaluation of the quality of proxy informations in the area of geriatric dermatology.

Also a General Practice Research Database based study from the United Kingdom,21 reports a moderately decreasing lifetime prevalence of psoriasis for individuals $>70$ years old. The authors attributed this finding either to an attenuating clinical burden of the disease with age leading to diagnostic gaps or to excess cumulative mortality of psoriatics. However, the recently reported constellation of decreasing discharge rates for psoriasis patients despite increasing admission numbers of patients with psoriasis history as a function of age, ${ }^{29}$ in connection to the fact that no more than $5 \%$ of all psoriasis patients will present with disease-onset after the age of 70,30 favors the former of the aforementioned explanations. A third explanation for a decreasing prevalence of psoriasis in cross-sectional studies as a function of age is that of increasing incidence of the disease as a function of calendar years. Actually a recent study demonstrated increasing age-specific prevalence rates of the disease in cohorts of younger generations. ${ }^{20}$ Studies focusing on trends in the macro-epidemiological characteristics of psoriasis are required in order to resolve this question.

Finally, our present survey permits, to the best of our knowledge for the first time in the literature, an approximate estimation of the prevalence of psoriasis in a Greek population. With only one exception, ${ }^{17}$ all relevant studies from other geographical regions, report agespecific prevalence rates of psoriasis in individuals $>70$ years old roughly equal 18,21 to twice as high ${ }^{19}$ compared to the mean prevalence in the corresponding whole populations. Accordingly our current measurement for individuals 70-89 years old (3.3\%) predicts a mean prevalence of psoriasis for the Greek population of about 1.5-3.0\%, which is comparable to that reported from other European regions. ${ }^{10-12}$

The main limitations of the present study are the relatively small size of the survey population and the inclusion of elderly individuals with adequate general, mental and physical performance, thus excluding chronically ill, hospitalized persons. On the contrary, measuring the prevalence of skin disorders by the selfreporting questionnaire approach seems not to bias the results of this survey because studies applying this methodology lead to essentially the same estimates of prevalence of skin diseases in the population as studies applying the patients examination by a physician' approach.1,7 Morbidity related to the aged skin, including skin cancer, is an emerging health problem in the aging population of many societies. The aforementioned difficulties in attaining reliable data on skin morbidity of older people could be partly compensated with the report of small-scale, targeted epidemiological surveys, like the present one. With the present report the need for focused gerontological research in the controversial issue of psoriasis prevalence and burden in the elderly is emphasized.

\section{References}

1. Rea JN, Newhouse ML, Halil T. Skin disease in Lambeth: a community study of prevalence and use of medical care. Br J Prev Soc Med 1976;30:107-14.

2. Meding B. Normal standards for dermatological health screening at places of work.
Contact Dermatitis 1992;27:269-70.

3. Bibgefors K, Lindberg M, Isacson D. Selfreported dermatological problems and use of prescribed topical drugs correlate with decreased quality of life: an epidemiological survey. Br J Dermatol 2002;147:285-90.

4. Schaefer I, Rustenbach SJ, Zimmer L, Augustin M. Prevalence of skin diseases in a cohort of 48,665 employees in Germany. Dermatology 2008;217:169-72.

5. Yalçin B, Tamer E, Gür Toy G et al. The prevalence of skin diseases in the elderly: analysis of 4099 geriatric patients. Int J Dermatol 2006;45:672-6.

6. Weismann K, Krakauer R, Wanscher B. Prevalence of skin diseases in the old. Acta Derm Venereol 1980;60:352-3.

7. Johnson MLT. Skin Conditions and Related Need for Medical Care among Persons 174 years, United States, 1971-1974. Vital and Health Statistics: Series 11, No 212. US Department of Health, Education and Welfare publication No. (PHS) 79-1660; National Center for Health Statistics 1978:1-72.

8. Basra MK, Shahrukh M. Burden of skin diseases. Expert Rev Pharmacoecon Outcomes Res 2009;9:271-83.

9. Beauregard S, Gilchrest BA. A survey of skin problems and skin care regimens in the elderly. Arch Dermatol 1987;123:163843.

10. Farber EM, Nail L. Epidemiology: natural history and genetics. In: Roenigk HR Jr, Maibach HI (eds), Psoriasis, 3rd ed., New York: Marcel Dekker; 1998. p. 107-57.

11. Naldi L. Inflammatory skin diseases IV: Psoriasis. In: HC Williams, DP Strachan (eds) The Clallenge of DermatoEpidemiology., Boca Raton-New York: CRC Press; 1997. p.175-90.

12. Gundjonsson JE, Elder JT. Psoriasis: epidemiology. Clin Dermatol 2007;25:535-46.

13. Lowes MA, Bowcock AM, Krueger JG. Pathogenesis and therapy of psoriasis. Nature 2007;445:866-73.

14. Finlay AY, Coles EC. The effect of severe psoriasis on the quality of life of 369 patients. Br J Dermatol 1995;132:236-44.

15. Sambogna F, Gisondi P, Melchi CF et al. Prevalence of symptoms experienced by patients with different clinical types of psoriasis. Br J Dermatol 2004;151:594-9.

16. http://ec.europa.eu/health/ph-projects/2001/promotion/fp-promotion_2001_ annex 3_02_en.pdf. Accessed:0ctober 26, 2010

17. Ferrándiz C, Bordas X, García-Patos V et al. Prevalence of psoriasis in Spain (Epiderma Project: phase I). J Eur Acad Dermatol Venereol 2001;15:20-3.

18. Bell LM, Sedlack R, Beard MC et al. Incidence of psoriasis in Rochester, Minn 1980-1983. Arch Dermatol 1991;127:1184- 
7.

19. Chang Y-T, Chen T-J, Liu P-C et al. Epidemiological study of psoriasis in the national health insurance database in Taiwan. Acta Derm Venereol 2009;89:2626.

20. Icen M, Crowson CS, McEvoy MT et al. Trends in incidence of adult-onset psoriasis over three decades: a population-based study. J Am Acad Dermatol 2009;60:394401.

21. Gelfand JM, Weinstein R, Porter SB et al. Prevalence and treatment of psoriasis in the United Kingdom. A population-based study. Arch Dermatol 2005;141:1537-41.

22. Braathen LR, Botten G, Bjerkedal T. Prevalence of psoriasis in Norway. Acta Derm Venereol 1989;142:5-8.

23. Kavli G, Stenvold SE, Vandbakk Ø. Low prevalence of psoriasis in Norwegian Lapp population. Acta Derm Venereol 1985;65: 262-3.

24. Duffy DL, Spelman LS, Martin NG. Psoriasis in Australian twins. J Am Acad Dermatol 1993;29:428-34.

25. Augustin M, Reich K, Glaeske G et al. Comorbidity and age-related prevalence of psoriasis: analysis of health insurance data in Germany. Acta Derm Venereol 2010;90:147-51.

26. The Medical Research Council Cognitive Function and Ageing Study. Survey into health problems of elderly people: multivariate analysis of concordance between self-report and proxy information. Int $\mathrm{J}$ Epidemiol 2000;29:698-703.

27. Neumann PJ, Araki SS, Gutterman EM. The use of proxy respondents in studies of older adults: lessons, challenges, and opportunities. J Am Geriatr Soc 2000;48:1646-54.

28. Corder LS, Woodbury MA, Manton KG. Proxy response patterns among the aged: effecys on estimates of health status and medical care utilization from the 1982 1984 long-term care surveys. J Clin Epidemiol 49;2:173-82.

29. Mazzatenta C, Giorgi D, Particelli S et al. Psoriasis in Italy: how many patients have severe cutaneous psoriasis? J Eur Acad Dermatol Venereol 2010;24:94-5.

30. Kawada A, Tezuka T, Nakamizo Y et al. A survey of psoriasis patients in Japan from 1982 to 2001. J Dermatol Sci 2003;31:5964. 